RETRACTION NOTE

\title{
Retraction Note: MicroRNA-23a enhances migration and invasion through PTEN in osteosarcoma
}

\author{
K. Tian, R. Di and L. Wang \\ (c) The Author(s), under exclusive licence to Springer Nature America, Inc. 2021 \\ Cancer Gene Therapy (2021) 28:1228; https://doi.org/10.1038/s41417-021-00363-z
}

Retraction to: Cancer Gene Ther https://doi.org/10.1038/ cgt.2015.27, published online 10 July 2015

The Editor-in-Chief has retracted this article because it shows significant overlap with a number of previously published articles by different authors $[1,2]$ and articles by different authors that were simultaneously under consideration $[3,4]$. There are also concerns with a number of figures, specifically:

- Figure 1B: these two mice appear to be identical to the two mice in Figure 1B of [1];

- Figure 1D: the two panels appear to be identical to Figures 5A and $5 \mathrm{~B}$ of [1];

- Figure 1E: The two panels appear to be identical to Figures $5 \mathrm{C}$ and $5 \mathrm{E}$ of [1];

- Figure $2 C$ appears to be identical to Figures $2 C$ and $2 B$ of [1];

- Figure 2D: multiple bands appear to be identical to the bands in Figure 2D of [1];

- Figure 2F: the western blots appear to be identical to Figure 2B of [1];

- Figure 2G: multiple bands appear to be identical to the bands in Figure $2 \mathrm{C}$ of [1];

- Figure 3a appears to be identical to Figure 5 of [2];

- Figure $3 \mathrm{~b}$ appears to be identical to Figure $4 \mathrm{~A}$ of [2];

- Figure 3d appears to be identical to Figure $4 C$ or [2];

- Figure 4 appears to be identical to Figure 3 of [2].

- Figure 5B: the tumors appear to be identical to tumors appearing in Figure 7B of [1];

- Figure $5 \mathrm{C}$ appears to be identical to the upper row and bottom row of figures in Figure 5D of [1];
Additionally, the article states that this study was approved was by the Animal Care Committee of Xinxiang Medical University, but none of the authors are affiliated with that institution. The Editorin-Chief therefore no longer has confidence in the reliability of the article.

The authors have not responded to correspondence regarding this retraction.

\section{REFERENCES}

1. Bao L, Yan Y, Xu C, Ji W, Shen S, Xu G. et al. MicroRNA-21 suppresses PTEN and hSulf-1 expression and promotes hepatocellular carcinoma progression through AKT/ERK pathways. Cancer Lett. 2013;337:226-36. https://doi.org/10.1016/j. canlet.2013.05.007.

2. Sun Z, Meng C, Wang S. et al. MicroRNA-1246 enhances migration and invasion through CADM1 in hepatocellular carcinoma. BMC Cancer. 2014;14:616. https:// doi.org/10.1186/1471-2407-14-616.

3. Yang Z, Wang R, Zhang T, Dong X. MicroRNA-126 regulates migration and invasion of gastric cancer by targeting CADM1. Int J Clin Exp Pathol. 2015;8:8869-80.

4. Ruoming W, Zhen Y, Tengteng Z. et al. RETRACTED ARTICLE: Tumor suppressor microRNA-31 inhibits gastric carcinogenesis by targeting Smad4 and SGPP2. Cancer Gene Ther. 2015;22:564-72. https://doi.org/10.1038/cgt.2015.41.

\section{ADDITIONAL INFORMATION}

Correspondence and requests for materials should be addressed to L.W.

Reprints and permission information is available at http://www.nature.com/ reprints 